\title{
CONDILOMA VIRAL EN LENGUA: PRESENTACIÓN DE UN CASO CLÍNICO Y REVISIÓN BIBLIOGRÁFICA
}

\author{
LINGUA CONDYLOMA: CASE REPORT PRESENTATION AND LITERATURE REVIEW
}

Rubén Rozas-Llerena', Raúl Sebastian-Ayala²

\begin{abstract}
RESUMEN
El condiloma acuminado es una enfermedad de transmisión sexual causada por el virus del papiloma (VPH). Se encuentra con frecuencia en la región ano-genital y es poco frecuente en la cavidad bucal. Sin embargo, el aumento de la actividad sexual oral ha favorecido aún más la aparición de PVH en la mucosa oral. Este informe describe un condiloma en la cavidad oral (lengua) de un hombre de 43 años con antecedentes de práctica sexual oral, cuyo diagnóstico se confirmó mediante una biopsia.
\end{abstract}

Palabras clave: VPH; Condiloma; Condiloma en lengua; Enfermedad de transmisión sexual. (fuente: DeCS BIREME)

\begin{abstract}
The acuminated condyloma is a sexually transmissible disease caused by the Papilomavirus (HPV). It is frequently found in the anus-genital region and rare in the mouth cavity. However, the increase of the oralsexual activity has even more favored the occurrence of the PVH in the oral mucous. This report describes a condyloma I the oral cavity (tongue) of a 43 year old man with a history of oral sex practice, which diagnostic was confirmed by a biopsy.
\end{abstract}

Key words: HPV; Condyloma; Lingua condyloma; Sexually transmitted diseases. (source: MeSH NLM)

\section{INTRODUCCIÓN}

El condiloma es un término que describe a una enfermedad de transmisión sexual que se contagia por el Virus del Papiloma Humano (VPH) también se denomina condiloma acuminado una lesión similar a una verruga carnosa irregular. Esta enfermedad afecta a hombres y mujeres que se encuentran sexualmente activos. Se contagia por contacto sexual, anal, oral y vaginal con personas infectadas. Este virus suele contagiarse sin embargo no hay evidencia alguna de estar infectados, la lesiones tipo verruga o condiloma aparecen en un menor porcentaje con lesiones visibles en el pene, vulva, cuello cervical, ano e inclusive en la cavidad orofaringea. El diagnostico se realiza por biopsia extirpándose totalmente la lesión. Prevención evitar el intercambio de parejas, usar preservativo, realizarse un diagnóstico citológico de Papanicolaou.

\section{CASO CLÍNICO}

Paciente de sexo masculino de 43 años de edad, quien refiere desde hace 6 meses ha notado una pequeña tumoración en el dorso de la lengua, de crecimiento lento, no doloroso y en la actualidad refiere que la tumoración mide $4 \mathrm{~cm}$ de diámetro mayor, ningunas otras molestias. El examen físico se aprecia en la región dorsal de la lengua una lesión elevada de color grisáceo, bordes irregulares, no ulcerada y que mide $4 \mathrm{~cm}$ de diámetro mayor. 


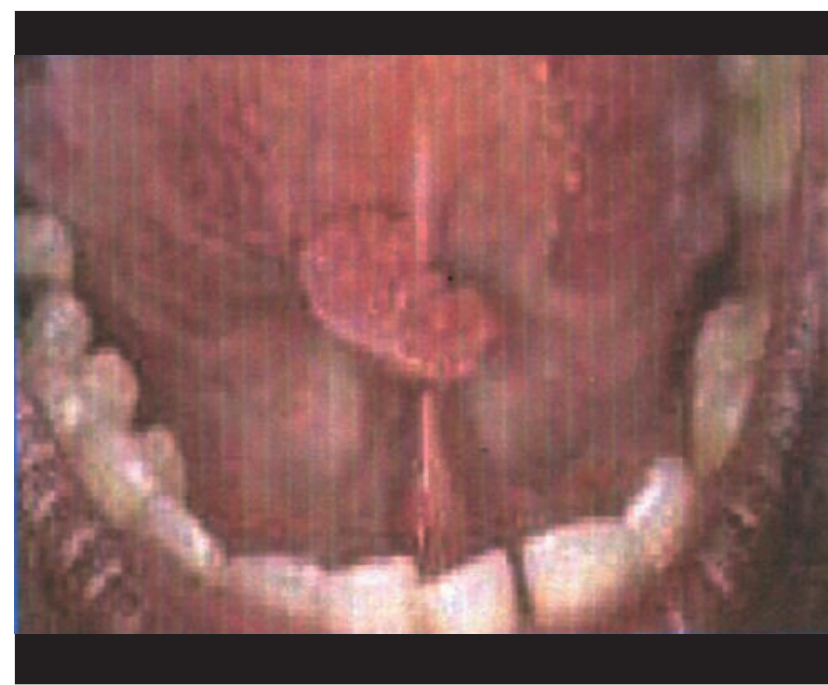

Figura 1. Macroscopia.

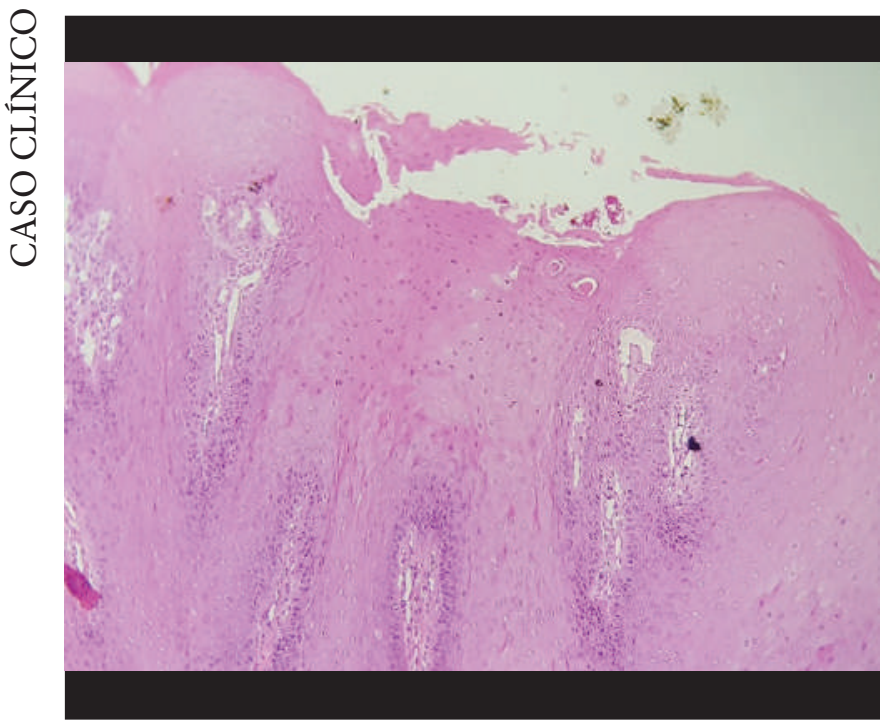

Figura 2. Microscopía: Hiperqueratosis, Paraqueratosis, Acantosis, Papilomatosis, Coilocitos.

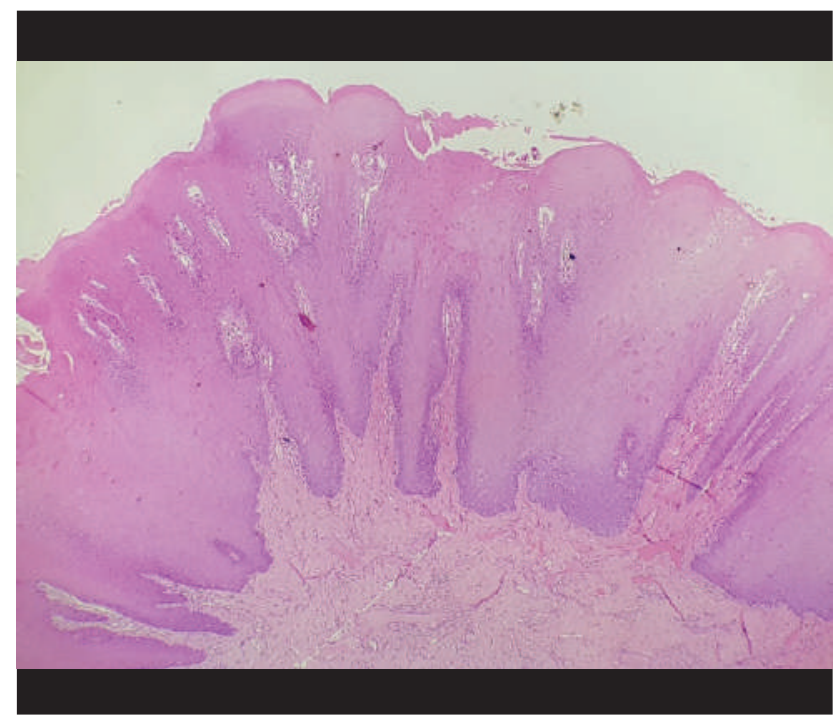

Figura 2. Microscopía: Hiperqueratosis, Paraqueratosis, Acantosis, Papilomatosis, Coilocitos.

\section{DISCUSIÓN}

El Virus del Papiloma Humano (PVH) es un virus DNA que pertenece a la familia papovaviridae, del género papiloma virus.

Se han descrito más de 160 genotipos diferentes, los cuales están definidos por la variabilidad de sus genes Eg, L1. El periodo de incubación varía entre 3 semanas a 8 meses con un promedio de 3 meses ${ }^{1,2,3,4}$. Ver clínicamente la presencia del papiloma virus humano se observa con mayor frecuencia en labio superior, frenillo lingual, dorso de la lengua como en el presente caso, labio inferior y comisuras ${ }^{5,6,7,8}$. Los condilomas son las lesiones clínicas más frecuentes los cuales se caracterizan por tener la formación de una colifor o presentarse como verrugas vulgares. La vía de transmisión la ocasionan las practicas orogenitales contagiadas por el PVH de los más de 100 genotipos del PVH, se han encontrado 16 con lesiones bucales $1,2,3,4,6,7,7,10,11,13,16,18,31,32,33,35,57$; el 13 y 32 son exclusivas de la cavidad bucal. La mayoría de esos virus, son de bajo riesgo (no oncogénicos) asociados a lesiones papilomatosas benignas: el 6 y 11 estan asociados a papiloma bucal, el 6 y 4 a verruga vulgar, 11 al condiloma acuminado, 13 y 32 a la hiperplasia epitelial focal (tienen bajo potencial de progresión maligna). En contraste los genotipos de alto riesgo (oncogénicos) como el 16, 18,31,33 y 35 estan asociados a leucoplasias y carcinoma escamocelular. Los tipos 16 y 18 se encuentran en la mayoría de los carcinomas escamocelulares bucales (80\%), mientras que los genotipos 31,33 y 35 son menos frecuentes (3\%). Se ha demostrado que el tabaco y alcohol son factores asociados al cáncer bucal9,10,11,12,13.

Para el diagnostico de identificación adecuada de los tipos virales se utilizan las siguientes técnicas:

a) Hibridación in situ

b) La prueba de Southern Blot

c) La técnica de reacción de polimerasa en cadena (alto rango de sensibilidad) puede detectar menos de una copia de DNA viral por célula.

\section{CONCLUSIÓN}

El paciente presento manifestaciones clínicas no concluyentes de condiloma viral por PVH, por lo que se realizó la biopsia para su diagnóstico adecuado.

Es importante realizar una historia clínica completa donde se interrogue los hábitos y costumbres sexuales tanto en mujeres como en hombres. 
Contribuciones de autoría: Los autores participaron en la concepción, diseño, redacción, revisión crítica y aprobación de la versión final del artículo.

Financiamiento: Autofinanciado.

Conflicto de interés: Los autores declaran no tener conflicto de interés en la publicación de este artículo.

Recibido: 07 de noviembre del 2018

Aprobado: 18 de diciembre del 2018

Correspondencia: Rubén Rozas Llerena

Dirección: Calle Monserrate Este-Urb. Las Gardenias Santiago de Surco

Celular: +51999725616

Correo:rubenrozasllerena1@hotmail.com

\section{REFERENCIAS BIBLIOGRÁFICAS}

1. Delgado Quiñones EG. Residente Medicina Familiar. Instituto Mexicano del Seguro Social (1955) Guadalajara Jalisco. México

2. Profesora Titular Curso de Especialización en Medicina Familiar IMSS. México

3. Director del Centro de Investigacion Educativa y Formacion Docente. IMSS. Jalisco. México

4. Médico Encargado de APAEDOM - ISSSTE. Jalisco. México

5. Palma I. Epidemiología del virus del Papiloma Humano. Rev Paceña Med Fam 2006; 3(4):67-70.

6. Fernandez E, Obanza W. Condiloma Acuminados. Guías Clínicas 2003; $3(33)$

7. Ronell E. Bologna-Molina R; Castañeda-Castaneira N.Virus del Papiloma humano y su asociación con cáncer bucal. Rev. Med. Inst. Mex Seguro Soc 2006; 44 (2): 147 - 153
8. Carr J, Gyorfi T. Human papilloma virus. Epidemiology, transmission and pathogenesis. Clin Lab Med 2000; 20: 235 - 255

9. Lazzari CM, Krug LP, Quadros OF, Baldi CB, Bozzetti MC, Human papillomavirus frequency in oral ephitelial lesions. J Oral Pathol Med 2004; 33 (5): 260 - 263.

10. Chappuis JM, Papa BM, Maldonado MS, Consigli JE. Patologia blanca de la mucosa oral. Arch Argent Dermatol 1998; 48: 209 - 33.

11. Premoli-de-Percoco G, Christensen R, Human Papillomavirus in Oral Verrucal-PApillary Lesions. Pathologica 1992; 84:383-92

12. Camargos AF, Hugo de Melo V. Ginecología ambulatorial. Belo Horizonte: Coopamed. 2001; $397-400$.

13. Tatti SA, Belardi G, Marini MA, Eiriz A, Chase LA, Ojeda J et al. Consenso en la metodología diagnóstica y terapéutica para las verrugas anogenitales. Revista Obstetricia y Ginecología Latino - americanas 2001; 59 (3): $117-31$.

Consulte la Versión Electrónica de la Revista: Facultad de Medicina Humana Universidad Ricardo Palma

http://revistas.urp.edu.pe/index.php/RFMH<smiles>C1=[In]CC1</smiles>

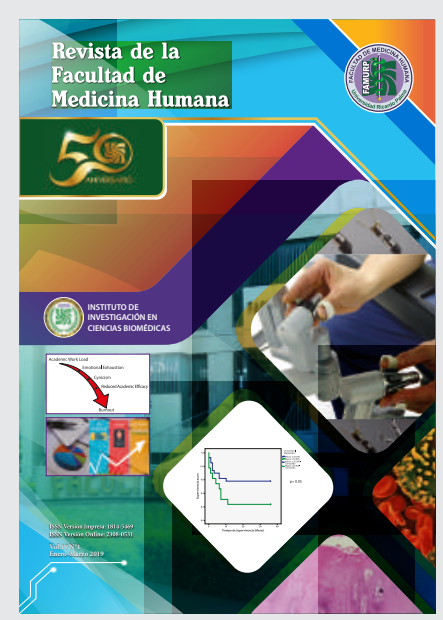

